\title{
Apolipoprotein E Genotype in Patients with Alzheimer's Disease: Implications for the Risk of Dementia Among Relatives
}

Lindsay A. Farrer, $\mathrm{PhD},{ }^{*}+\mathrm{L}$. Adrienne Cupples, $\mathrm{PhD}, \dagger$ Cornelia M. van Duijn, $\mathrm{PhD}, \S$ Alexander Kurz, MD, Reinhilde Zimmer, MD," Ulrich Müller, MD, ${ }^{* *}$ Robert C. Green, MD, $\dagger$ Valerie Clarke, ${ }^{\dagger \dagger}$

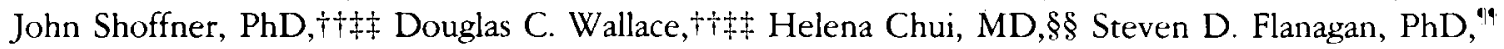
Ranjan Duara, MD, ,** Peter St. George-Hyslop, MD, $\dagger+\dagger$ Sanford A. Auerbach, MD,*

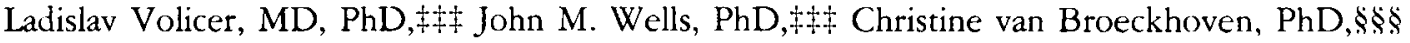
John $\mathrm{H}$. Growdon, MD $\ddagger$ and Jonathan L. Haines, $\mathrm{PhD} \ddagger^{199}$

Numerous studies have shown that the risk of Alzheimer's disease (AD) is associated with the dose of the $\varepsilon 4$ allele of apolipoprotein $\mathrm{E}$ (ApoE). However, more than one third of AD patients lack $\varepsilon 4$ and many persons having $\varepsilon 4$ survive cognitively intact to old age. We evaluated the lifetime risk of disease in 3,999 first-degree relatives of 549 probands who met the criteria for probable or definite AD and whose ApoE genotypes were known. ApoE genotypes for relatives were not determined. After age 65 the risk among relatives was proportional, as much as 7 to $10 \%$ at age 85, to the number of $\varepsilon 4$ alleles present in the proband. Risks to relatives of $A$ poE $2 / 2$ and 2/3 probands were nearly identical at all ages to risks for relatives of ApoE 3/3 probands. The expected proportion of relatives having at least one $\varepsilon 4$ allele was calculated for each genotype group based on the distribution of parents, sibs, and offspring in the sample. Among relatives in the ApoE 3/3 group, the lifetime risk for AD by age 90 was three times greater than the expected proportion of $\varepsilon 4$ carriers, suggesting that factors other than ApoE contribute to AD susceptibility. Furthermore, the $44 \%$ risk of $\mathrm{AD}$ by age 93 among relatives of $\mathrm{ApoE} 4 / 4$ probands indicates that as many as $50 \%$ of people having at least one $\varepsilon 4$ allele do not develop AD. We also found that among male relatives, risk of AD in the ApoE 3/4 group was similar to that for the ApoE $3 / 3$ group but significantly less than the risk for the ApoE 4/4 group. In contrast, among female relatives the risk for the ApoE 3/4 group was nearly twice that for the ApoE $3 / 3$ group and identical to the risk for the ApoE $4 / 4$ group. These findings are consistent with a sex-modification effect of the E4 isoform on disease susceptibility.

Farrer LA, Cupples LA, van Duijn CM, Kurz A, Zimmer R, Müller U, Green RC, Clarke V, Shoffner J, Wallace DC, Chui H, Flanagan SD, Duara R, St. George-Hyslop P, Auerbach SA, Volicer L, Wells JM, van Broeckhoven C, Growdon JH, Haines JL. Apolipoprotein E genotype in patients with Alzhcimer's disease: implications for the risk of dementia among relatives. Ann Neurol 1995;38:797-808

Alzheimer's disease $(\mathrm{AD})$ is a degenerative disorder that causes loss of memory and cognition in more than 6 to $10 \%$ of the population over the age of $65[1$, 2]. Increased risk of disease is associated with several epidemiological risk factors (for a review see [2]); how- ever, none of these has been consistently observed. The strongest predictors of disease risk are age and family history of AD.

Molecular genetic studies have implicated at least four genes in disease pathogenesis. Mutations in three
From the Departments of *Neurology and $\div$ Epidemiology and Biostatistics, Boston University School of Medicine, Boston; \$Department of Neurology, Harvard University School of Medicine, Boston: \$Department of Epidemiology and Biostatistics, Erasmus University, Rotterdam, The Netherlands; 'Psychiatrische Klinik der Technischen Universität München, Munich; **Institut für Humangenetik der Justus-Liebig-Universität, Gießen, Germany; Departments of + Neurology and + Tenetic and Molecular Medicine, Emory University, Atlanta, GA; $\$ \$$ University of Southern California, Los Angeles;" Beckman Research Institute of the City of Hope, Duarte, CA; ***University of Miami School of Medicine, Miami, FL; $\dagger+$ Department of Neurology, University of Toronto, Toronto, Ontario, Canada; $¥+$ Geriatric Research Education and Clinical Center, Edith Nourse Rogers Memorial Veterans Hospital, Bedford, MA; $\$ \$ \$$ Neurogenetics Laboratory, Born Bunge Laboratory, University of Antwerp, Antwerp, Belgium; and "Molecular Neurogenetics Unit, Massachusetts General Hospital, Boston, MA.
Received Apr 28, 1995, and in revised form Jun 7 and 30. Accepeed for publication Jul 13, 1995.

Address correspondence to Dr Farret, Department of Neurology. Boston University School of Medicinc, Boston, MA 02118. 
of these, the chromosome 21 gene encoding $\beta$-amyloid precursor protein, the $\mathrm{AD} 3$ gene on chromosome 14 , and the SMT2 gene on chromosome 1, account for a relatively small group of patients with autosomal dominantly transmitted disease that manifests usually before the age of 65 [3-7]. The $\varepsilon 2$ and $\varepsilon 4$ alleles of the apolipoprotein $\mathrm{E}(\mathrm{ApoE})$ gene are in linkage disequilibrium with $\mathrm{AD}$ in patients from various parts of the world with early onset [8] and late onser [9] of symptoms (see [10] for an extensive list of studies). The biological basis for these associations is unknown. In vitro experiments suggest that the E3 (and E2) isoforms interact metabolically with microtubuleassociated proteins in a manner different from the $\mathrm{E} 4$ isoform $[11,12\}$. However, because neurons do not express ApoE messenger RNA (mRNA) and the cellular trafficking of ApoE in neurons is poorly understood, this explanation for the role of ApoE in $\mathrm{AD}$ pathogenesis is still speculative. Alternatively, aberrant interaction between ApoE and $\beta$-amyloid may be a critical step in the disease [13].

In spite of the compelling evidence for a dose effect of $\varepsilon 4$ on risk and age at onset of $A D$ [14], the sensitivity and specificity of the association are modest [15]. Here, sensitivity refers to the proportion of individuals with $\varepsilon 4$ among those who will develop AD; specificity refers to the proportion of individuals without $\varepsilon 4$ among those who will not develop disease. Reduced sensitivity of $\varepsilon 4$ for $A D$ suggests that the disorder in many persons is caused by factors independent of ApoE. The observation that not all persons who have the $\varepsilon 4$ allele develop $\mathrm{AD}$ (i.e., reduced specificity) suggests that either the effect of $\varepsilon 4$ is modulated by other risk factors or such persons in whom the disease is apparently nonpenetrant have not survived to their eventual onset age.

To address the questions of sensitivity and specificity of ApoE on risk of $\mathrm{AD}$, we investigated the relationship between lifetime risk of disease, ApoE genotype, and sex in a group of 549 families in which the probands met rigorous diagnostic criteria and were genotyped for ApoE.

\section{Materials and Methods \\ Subjects}

Two patient cohorts were recruited for this study. One group includes 378 participants in the Multi-Institutional Research in Alzheimer Genetic Epidemiology (MIRAGE) Study. MlRAGE centers are tertiary care units that evaluate patients referred for a memory disorder. The groups participating in this study are the Alzheimer's Disease Resource and Referral Center at the Boston University Medical Center (BU); the Geriatric Research Education and Clinical Center (GRECC), Edith Nourse Rogers Memorial Veterans Hospital, Bedford, MA (Bedford); the Wesley Woods Center at Emory University, Aclanta, GA (Emory); the Memory Disorders Unit of the Massachusetts General Hospital (MGH); the Wien Cen- ter at Mount Sinai Medical Center in Miami Beach, FL (Miami); the Southern California Alzheimer's Disease Diagnostic and Treatment Center at the Rancho Los Amigos Medical Center, Downey, CA (USC); and the Psychiatry Clinic at the Technical University of Munich, Germany (Munich).

MIRAGE patients were consecutively ascertained from the clinic populations at each of the centers and underwent a rigorous diagnostic evaluation including a neurological examination and appropriate neuropsychological, laboratory, and brain imaging tests. Eligible probands had a rating of 1 (59 subjects) or 2 (319) subjects) on the A axis of the MIRAGE AD rating scale [16]. These ratings correspond to National Institute of Neurological and Communicative Disorders and Stroke/Alzheimer's Disease and Related Disorders Association (NINCDS/ADRDA) criteria for definite (i.e., autopsy-confirmed) or probable $A D$, respectively [17]. Interrater reliability of diagnosis among MIRAGE sites using this rating scale was found to be sufficiently high [16]. Information on family history of dementia among first-degree relatives (i.e., parents, siblings, and children) was collected from a primary informant (usually a spouse or child, and occasionally a sibling) using standardized questionnaire instruments administered by direct or telephone interview. Multiple informants were sought to supplement and verify these responses. Relatives were considered to be affected if they met criteria for ratings 1 to 4 on the MIRAGE AD rating scale. Ratings of 3 or 4 correspond to varying degrees of certainty in the diagnosis of possible AD. Additional details regarding patient sampling and evaluation can be found elsewhere (V. S. Rao and colleagues, unpublished manuscript, 1995). Of the 1,150 probable and definite AD patients at these centers for whom family history information was available, tissue samples for DNA analysis were obtained for 59 autopsied subjects and 319 subjects who were evaluated in the clinic between July 1993 and April 1995. Selected characteristics of the probands are given in Table 1.

The second subject group was composed of 171 patients enrolled in a population-based study in the Netherlands [18]. All of these patients had onset of symptoms before the age of 65 years and are thus considered to have early-onset AD. Details of the study design and diagnostic criteria have been published $[18,19]$. Probands were evaluated by two physicians who independently confirmed the diagnosis of probable AD using a standard protocol similar to NINCDS/ADRDA and MIRAGE criteria. Our previous studies showed that lifetime risk and patterns of familial aggregation of illness among first-degree relatives of these patients $[18]$ were similar to results obtained from studies of MGH patients [20, 21].

\section{ApoE Genotyping}

The ApoE assay for the AD cases was performed by polymerase chain reaction (PCR) applying the method of Wenham and coworkers [22] or van Duijn and colleagues [8]. The ApoE gene was amplified using conditions as described elsewhere $[8,23]$ (L. A. Farrer and colleagues, unpublished manuscript, 1995). The PCR product was digested with either $\mathrm{Hba}$ I or Cfo I following a standard procedure [24] and fragments were separated on a standard $6 \%$ nondenaturing polyacrylamide gel. ApoE genotype frequency data for the Dutch patient group have been reported [8]. 


\begin{tabular}{|c|c|c|c|c|c|}
\hline \multirow[b]{2}{*}{ Site } & \multicolumn{3}{|c|}{ Probands } & \multicolumn{2}{|c|}{ Relatives } \\
\hline & $\begin{array}{l}\text { No. of } \\
\text { Males }\end{array}$ & $\begin{array}{l}\text { No. of } \\
\text { Females }\end{array}$ & $\begin{array}{l}\text { Onset Age (yr) } \\
\text { (mean } \pm \text { std) }\end{array}$ & $\begin{array}{l}\text { No. } \\
\text { Affected }\end{array}$ & $\begin{array}{l}\text { No. } \\
\text { Unaffected }\end{array}$ \\
\hline Boston University & 23 & 37 & $70.8 \pm 8.0$ & 22 & 443 \\
\hline Bedford & 29 & 0 & $64.2 \pm 8.2$ & 5 & 196 \\
\hline Emory & 7 & 8 & $75.5 \pm 6.1$ & 16 & 95 \\
\hline Massachusetts General Hospital & 48 & 103 & $69.6 \pm 8.3$ & 106 & 1,102 \\
\hline Miami & 4 & 13 & $74.0 \pm 8.1$ & 11 & 127 \\
\hline Munich & 28 & 41 & $65.1 \pm 8.8$ & 16 & 431 \\
\hline Rotterdam & 56 & 115 & $57.8 \pm 5.0$ & 112 & 1,073 \\
\hline University of Southern California & 14 & 23 & $67.2 \pm 6.9$ & 28 & 216 \\
\hline Total & 209 & 340 & $65.3 \pm 9.2$ & 316 & 3,683 \\
\hline
\end{tabular}

\section{Estimation of Lifetime Risk and Age at Onset Distribution}

The lifetime risk of dementia and the age at onset distribution for first-degree relatives of the AD probands were estimated using a maximum likelihood procedure [25]. This method considers not only affected persons with known onset ages and unaffected persons with known censoring ages (i.e., those persons typically included in a Kaplan-Meier survival analysis [26]), but also persons for whom onset age or censoring age data are missing. In this study, 35 affected and 75 unaffected individuals $(2.75 \%$ of all relatives) were lacking these data but were able to be incorporated in the analysis. This method also allows for the possibilities that a proportion of relatives asymptomatic at the time of study may be susceptible and express the disease later in life and that some dead relatives may have died from causes unrelated to $A D$ although symptoms may have developed had they survived. All lifetime risks, mean ages at onset, and survival distributions reported here were estimated using this method.

Parameter estimates and their standard errors for the estimated lifetime risk and mean onset age were compared between subgroups of $\mathrm{AD}$ relatives at the oldest age common to both groups. Since asymptotically these maximum likelihood statistics have normal distributions, a large sample $Z$ statistic was used for these comparisons [27]. Test-based confidence intervals for risk ratios were computed using this $Z$ statistic. A log-rank statistic was used to test homogeneity of onset age distributions [28]. For the purpose of these analyses, probands were stratified by ApoE genotype. For some analyses, families of probands with an ApoE genotype of $2 / 2$ or $2 / 3$ were combined with families whose probands were $3 / 3$, and families of probands with $2 / 4$ were combined with $3 / 4$ families. Gender effects were evaluated by further stratification of the relatives by sex and sex of the proband. Interaction of ApoE genotype and sex on lifetime risk of AD was tested formally by proportional hazard regression analysis in the $97.25 \%$ of subjects who had known censoring ages [29]. Models were evaluated using the PHREG procedure of the SAS [30].

\section{Distribution of $\varepsilon 4$ among First-Degree Relatives}

To assess directly the proportion of the estimated lifetime risk of disease among relatives attributable to ApoE geno- type, one would need to have ApoE information on the relatives. This was not feasible because most parents and sibs are either deceased or otherwise unavailable for study. Genotyping children for ApoE is not warranted since most are too young to have expressed disease. However, the expected proportions of first-degree relatives of $A D$ patients having at least one ApoE $\varepsilon 4$ allele can be derived from the conditional probabilities of the possible mating types among parents and spouses of the probands having a specified ApoE genotype. For these analyses, we modeled ApoE genotype as a twoallele system with frequencies $\mathrm{p}$ and $\mathrm{q}$ for the non- $\varepsilon 4$ (i.e., $\varepsilon 2$ and $\varepsilon 3$ ) and $\varepsilon 4$ alleles, respectively, and assumed that the frequency of the $\varepsilon 4$ allele in parental chromosomes not inherited by the proband was 0.135 , that is, the same as in the general population [31]. Because the $\varepsilon 2$ allele accounts for less than $8 \%$ of the polymorphism in the general population [31], its frequency was combined with that for $\varepsilon 3$. Hardy-Weinberg equilibrium among the allele frequencies was assumed.

To calculate the proportion of a specific group of relatives (i.e., parents, sibs, or offspring) having the ApoE $3 / 4$ or $4 / 4$ genotype, the conditional probability of each possible mating type was multiplied by the proportion of relatives having the genotype, and these products were summed over all possible matings. The expected proportions of parents, sibs, and offspring having ApoE 3/4 and 4/4 genotypes are given in Table 2. The expected proportion of first-degree relatives having at least one $\varepsilon 4$ allele was then determined in a two-step process. First, within each proband genotype group the expected frequencies from Table 2 for each set of relatives were summed to calculate the total proportion of individuals having at least one $\varepsilon 4$ allele. Second, these proportions were adjusted for the relative frequencies of parents, sibs, and offspring in the sample.

\section{Results}

Over a life span of 96 years, the risk for dementia to first-degree relatives of all AD probands was $40.6 \pm$ $4.3 \%$ (Table 3). The estimated mean onset age for affected relatives was $80.8 \pm 1.4$ years. Stratification of the families by ApoE genotype of the proband revealed that relatives of probands having at least one $\varepsilon 4$ 


\begin{tabular}{|c|c|c|c|c|c|c|c|c|c|c|}
\hline \multirow[b]{3}{*}{$\begin{array}{l}\text { Proband's } \\
\text { Genotype }\end{array}$} & \multirow{2}{*}{\multicolumn{2}{|c|}{ Parents }} & \multirow{2}{*}{\multicolumn{2}{|c|}{ Spouse }} & \multicolumn{6}{|c|}{ Proportion of Relatives Having ApoE Genotype } \\
\hline & & & & & \multicolumn{2}{|c|}{ Parents } & \multicolumn{2}{|c|}{ Sibs } & \multicolumn{2}{|c|}{ Offspring } \\
\hline & $\begin{array}{l}\text { Possible } \\
\text { Mating }\end{array}$ & $\begin{array}{l}\text { Conditional } \\
\text { Probability }^{b}\end{array}$ & $\begin{array}{l}\text { Possible } \\
\text { Genotype }\end{array}$ & $\begin{array}{l}\text { Conditional } \\
\text { Probability }\end{array}$ & $\mathrm{X} 4$ & 44 & $\mathrm{X} 4$ & 44 & $\overline{\mathrm{X} 4}$ & 44 \\
\hline $\mathrm{XX}$ & $\begin{array}{l}\mathrm{XX} \times \mathrm{XX} \\
\mathrm{XX} \times \mathrm{X} 4 \\
\mathrm{X} 4 \times \mathrm{X} 4 \\
\text { Total }\end{array}$ & $\begin{array}{l}\mathrm{p}^{2} \\
2 \mathrm{pq} \\
\mathrm{q}^{2}\end{array}$ & $\begin{array}{l}\mathrm{XX} \\
\mathrm{X} 4 \\
44\end{array}$ & $\begin{array}{l}\mathrm{p}^{2} \\
2 \mathrm{pq} \\
\mathrm{q}^{2}\end{array}$ & $\begin{array}{l}0 \\
\mathrm{pq} \\
\mathrm{q}^{2} \\
\mathrm{q}\end{array}$ & $\begin{array}{l}0 \\
0 \\
0 \\
0\end{array}$ & $\begin{array}{l}0 \\
p q \\
1 / 2 q^{2} \\
p q+1 / 2 q^{2}\end{array}$ & $\begin{array}{l}0 \\
0 \\
1 / q^{2} \\
1 / q^{2}\end{array}$ & $\begin{array}{l}0 \\
p q \\
q^{2} \\
q\end{array}$ & $\begin{array}{l}0 \\
0 \\
0 \\
0\end{array}$ \\
\hline $\mathrm{X} 4$ & $\begin{array}{l}X X \times X 4 \\
X X \times 44 \\
X 4 \times X 4 \\
X 4 \times 44\end{array}$ & $\begin{array}{l}\mathrm{p}^{2} \\
\mathrm{pq} \\
\mathrm{pq} \\
\mathrm{q}^{2}\end{array}$ & $\begin{array}{l}X X \\
X 4 \\
44\end{array}$ & $\begin{array}{l}\mathrm{p}^{2} \\
2 \mathrm{pq} \\
\mathrm{q}^{2}\end{array}$ & $\begin{array}{l}1 / 2 \mathrm{p}^{2} \\
0 \\
\mathrm{pq} \\
1 / 2 \mathrm{q}^{2}\end{array}$ & $\begin{array}{l}0 \\
1 / p q \\
0 \\
1 / 2 q^{2}\end{array}$ & $\begin{array}{l}1 / 2 p^{2} \\
p q \\
1 / 2 p q \\
1 / 2 q^{2}\end{array}$ & $\begin{array}{l}0 \\
0 \\
1 / p q \\
1 / q^{2}\end{array}$ & $\begin{array}{l}1 / p^{2} \\
p q \\
1 / 2 q^{2}\end{array}$ & $\begin{array}{l}0 \\
1 / 2 q^{2} \\
1 / q^{2}\end{array}$ \\
\hline & Total & & & & $1 / 2$ & $1 / 39$ & $\frac{1+p q}{2}$ & $\frac{q+q^{2}}{4}$ & $1 \%$ & $1 / 2 \mathrm{q}$ \\
\hline 44 & $\begin{array}{l}X 4 \times X 4 \\
X 4 \times 44 \\
44 \times 44\end{array}$ & $\begin{array}{l}\mathrm{p}^{2} \\
2 \mathrm{pq} \\
\mathrm{q}^{2}\end{array}$ & $\begin{array}{l}\mathrm{XX} \\
\mathrm{X} 4 \\
44\end{array}$ & $\begin{array}{l}p^{2} \\
2 p q \\
q^{2}\end{array}$ & $\begin{array}{l}p^{2} \\
p q \\
0\end{array}$ & $\begin{array}{l}0 \\
p q \\
q^{2}\end{array}$ & $\begin{array}{l}1 / 2 \mathrm{p}^{2} \\
\mathrm{pq} \\
0\end{array}$ & $\begin{array}{l}1 / p^{2} \\
p q \\
q^{2}\end{array}$ & $\begin{array}{l}p^{2} \\
p q \\
0\end{array}$ & $\begin{array}{l}0 \\
\mathrm{pq} \\
\mathrm{q}^{2}\end{array}$ \\
\hline & Total & & & & $\mathrm{p}$ & $\mathrm{q}$ & $\frac{1-\mathrm{q}^{2}}{2}$ & $1 / p^{2}+q$ & $\mathrm{p}$ & q \\
\hline
\end{tabular}

${ }^{a} \mathrm{X}=82$ or 83.

${ }^{b} \mathrm{p}=$ frequency of $\mathrm{X}$ (i.e., $\varepsilon 2+\varepsilon 3$ ); $\mathrm{q}=$ frequency of $\varepsilon 4 ;$ Hardy-Weinberg equilibrium assumed, therefore $\mathrm{p}+\mathrm{q}=1$.

Table 3. Estimated Lifetime Risk of $A D$ and the Age at Onset Distribution among First-Degree Relatives of AD Probands Stratified by ApoE Genotype and among Control Subjects

\begin{tabular}{|c|c|c|c|c|c|c|c|}
\hline \multirow[b]{2}{*}{ Group } & \multirow{2}{*}{$\begin{array}{l}\text { No. of } \\
\text { Probands }\end{array}$} & \multicolumn{2}{|c|}{ No. of Relatives } & \multirow{2}{*}{$\begin{array}{l}\text { Oldest Onset } \\
\text { Age (yr) }\end{array}$} & \multirow{2}{*}{$\begin{array}{l}\text { Lifetime Risk } \\
\text { (SE) }\end{array}$} & \multirow{2}{*}{$\begin{array}{l}\text { Comparison Risk } \\
(\mathrm{SE})^{i}\end{array}$} & \multirow{2}{*}{$\begin{array}{l}\text { Mean Onset Age } \\
(y r)(S E)\end{array}$} \\
\hline & & Affected & Unaffected & & & & \\
\hline All & 549 & 316 & 3,683 & 96 & $0.406(0.043)$ & & $80.8(1.4)$ \\
\hline$\varepsilon 22 / \varepsilon 23 / \varepsilon 33$ & 225 & 95 & 1,508 & 96 & $0.360(0.085)$ & $0.274(0.047)$ & $83.7(2.8)$ \\
\hline$\varepsilon 24 / \varepsilon 34 / \varepsilon 44$ & 324 & 221 & 2,175 & 93 & $0.453(0.046)$ & $0.453(0.046)$ & $79.7(1.2)$ \\
\hline$\varepsilon 22 / \varepsilon 23$ & 40 & 14 & 270 & 85 & $0.178(0.053)$ & $0.178(0.053)$ & $76.7(2.5)$ \\
\hline$\varepsilon 33$ & 185 & 81 & 1,238 & 96 & $0.383(0.092)$ & $0.196(0.026)$ & $84.2(2.7)$ \\
\hline$\varepsilon 34$ & 228 & 155 & 1.546 & 93 & $0.458(0.056)$ & $0.295(0.026)$ & $80.4(1.4)$ \\
\hline$\varepsilon 44$ & 86 & 61 & 562 & 91 & $0.442(0.082)$ & $0.370(0.048)$ & $77.8(2.2)$ \\
\hline
\end{tabular}

${ }^{2}$ Risk at maximum age common to comparison groups (i.e., the smallest of the oldest onset ages); see text for groups being compared.

allele had an $18 \%$ greater risk of developing AD by age 93 than did relatives of probands lacking $\varepsilon 4$ ( $Z=$ $2.72, p=0.0066)$. The estimated mean onset ages of the two groups were not significantly different $(Z=$ $1.40, p=0.16)$. These findings suggest that although the relative proportion of early-and late-onset cases is similar among relatives of probands with or without the $\varepsilon 4$ allele, the risk of $\mathrm{AD}$ is higher in relatives of 84 probands for ages of 65 years and older (Fig 1 ). The relative risk for $\mathrm{AD}$ by the age of 93 for those with an affected relative with $\varepsilon 4$ compared with those with an affected relative lacking $\varepsilon 4$ is $1.65195 \%$ confidence interval $=1.2-2.4$ ).

At every age after 65 years, the risk of $A D$ among relatives was proportional to the number of $\varepsilon 4$ alleles present in the proband (Fig 2). At age 85 (the maximum onset age among affected relatives common to all genotype groups) the cumulative incidence of $A D$ among relatives of patients having ApoE genotype $2 / 2$ or $2 / 3$ was not significantly different from the risk among relatives of ApoE $3 / 3$ patients $(p=0.30)$. Relatives of probands having ApoE $3 / 3$ had a liferime risk of 0.20 of developing $\mathrm{AD}$ by age 85 . Risk of disease among relatives increased by 7 to $10 \%$ with the number of $\varepsilon 4$ alleles in the proband; however, only the difference berween the $3 / 3$ and $3 / 4$ groups was significant $(3 / 3$ vs $3 / 4: Z=2.69, p=0.0072 ; 3 / 4$ vs $4 / 4$ : $Z=1.37, p=0.17$ ). In fact, the entire distributions for the ApoE 3/4 and 4/4 groups were not significantly different (log-rank $\chi^{2}=1.00, p=0.32$ ). Although 


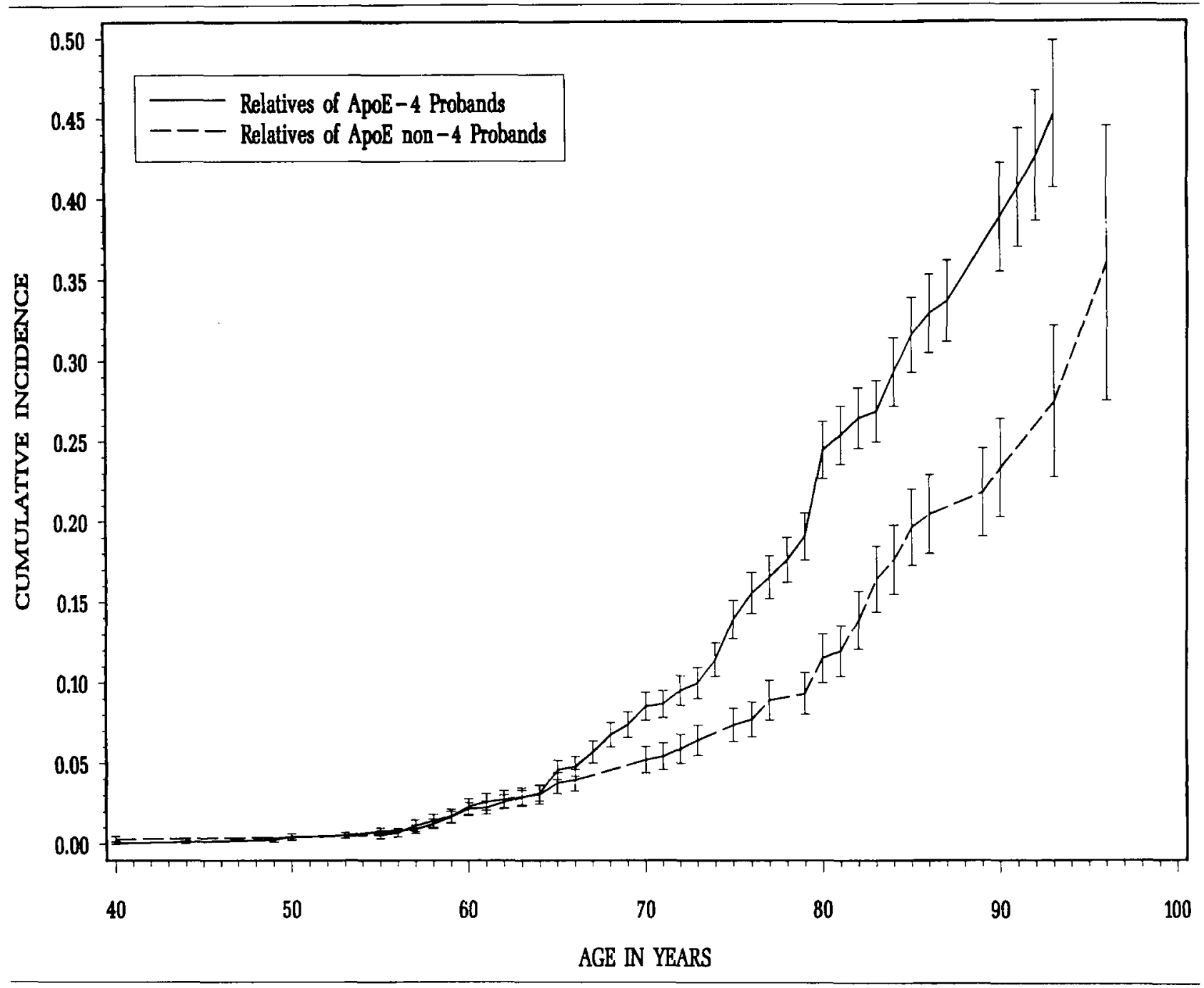

Fig 1. Estimated lifetime incidence of Alzbeimer's disease ( $A D$ ) in first-degree relatives of $A D$ probands with $A p o E 4$ and $A p o E$ non-4 genotypes. Vertical lines show' standard errors at each age value for onset in affected relatives.

Table 3 suggests a trend of decreasing onset age among affected relatives with dose of $\varepsilon 4$ in the proband, all pairwise comparisons between mean onset ages for relatives of $3 / 3,3 / 4$, and $4 / 4$ probands were not significant. Lifetime risk and the onset age distribution were not estimated for relatives of the 10 ApoE $2 / 4$ probands because results from such a small sample would not be accurate.

Estimates of the proportions of relatives having ApoE genotype $3 / 3$ or $3 / 4$ (see Table 2 ) and the observed distribution of relatives were used to derive the expected proportion of relatives having at least one $\varepsilon 4$ allele (Table 4). Approximately $13 \%$ of the 1,319 relatives of the $A D$ probands having ApoE $3 / 3$ are predicted to be $\varepsilon 4$ carriers. This estimate equals one half of the cumulative incidence of AD by age 90 in this group of relatives. These results indicate that famil- ial factors other than ApoE contribute to aggregation of $\mathrm{AD}$ in this group of families. In contrast, among relatives of ApoE 3/4 and 4/4 probands, the expected proportions of $\varepsilon 4$ carriers are 1.5 and 2.1 times greater, respectively, than the lifetime risk of $\mathrm{AD}$. Therefore, even after allowing for the possibility of onset of disease symptoms as late as age 90 , between 34 and $51 \%$ of $\varepsilon 4$ carriers are predicted to be cognitively normal. Comparisons of lifetime risk with the expected proportion of $\varepsilon 4$ carriers were not done for parents and sibs separately because the life risks for these groups of relatives were not significantly different, regardless of the ApoE genotype of the proband (data not shown).

For each ApoE genotype, lifetime risks of $\mathrm{AD}$ among relatives of male and female probands were not significantly different at the comparison age of 82 years (Table 5). However, stratification of the relatives by sex revealed that among probands having ApoE 3/4, female relatives had approximately twice the lifetime risk as male relatives of developing $A D$ by age $84(Z$ $=3.92, p=0.00009)$. The gender differences in risk 


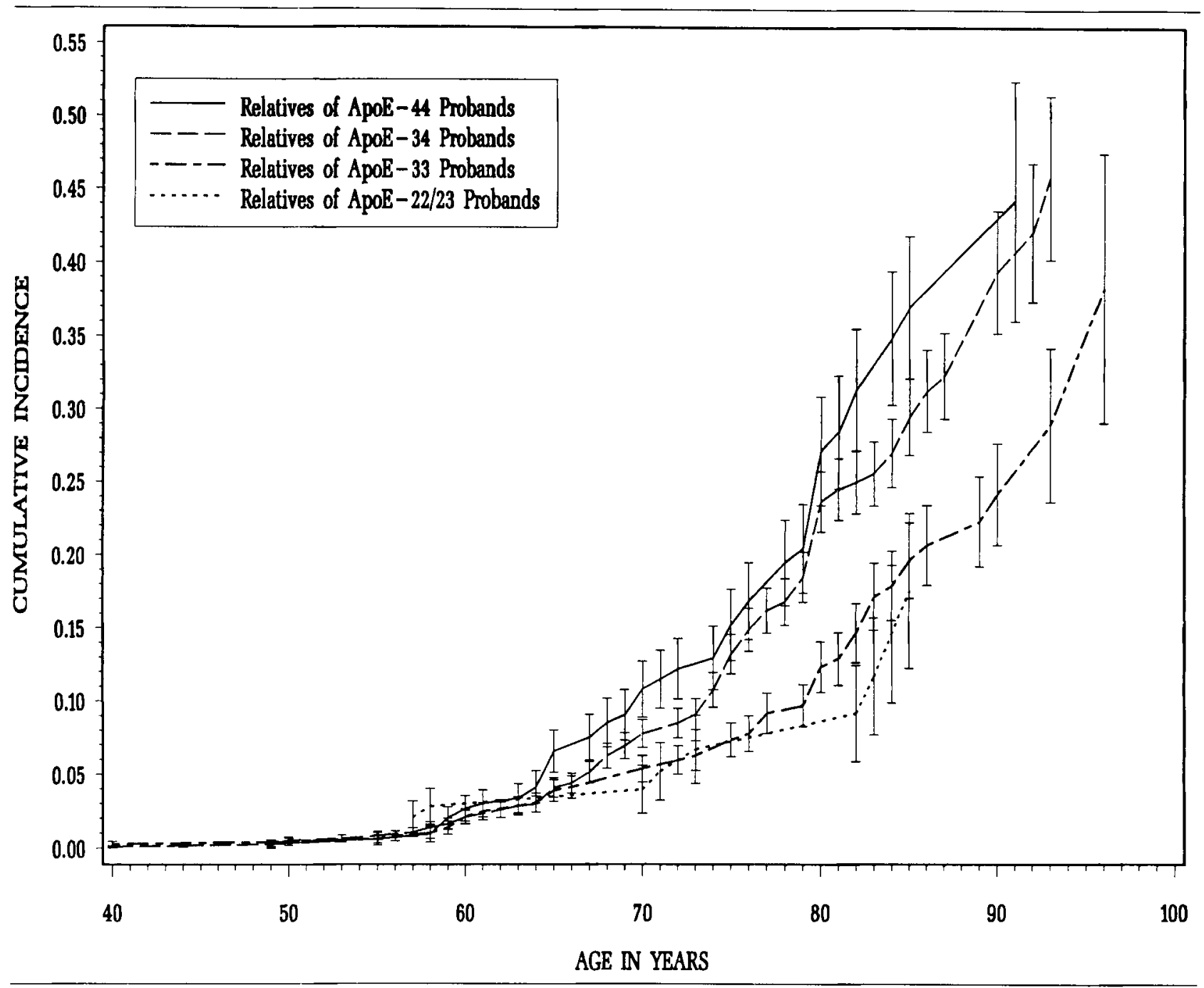

Fig 2. Estimated lifetime incidence of Alzbeimer's disease (AD) in first-degree relatives of $A D$ probands with $A p o E 2 / 2$ or $2 / 3$. ApoE 3/3. ApoE 3/4, and ApoE 4/4 genotypes. Vertical lines shou standard errori at each age value for onset in affected relatives.

Table 4. Comparison of Expected Proportion of Relatives Haring ApoE $\varepsilon 4$ with Lifetime Risk of AD

\begin{tabular}{|c|c|c|c|c|c|c|c|c|c|}
\hline \multirow{2}{*}{$\begin{array}{l}\text { Proband's } \\
\text { ApoE } \\
\text { Genotype }\end{array}$} & \multicolumn{4}{|c|}{ No. of Relatives } & \multicolumn{4}{|c|}{$\begin{array}{l}\text { Expected Proportion of Relatives Having } \\
\text { at Least } 1 \text { ApoE } \varepsilon 4 \text { Allele }\end{array}$} & \multirow{2}{*}{$\begin{array}{l}\text { Lifetime Risk (SE) } \\
\text { of AD in Relatives } \\
\text { at Age } 90\end{array}$} \\
\hline & Parents & Sibs & Offspring & Total & Parents & Sibs & Offspring & Total ${ }^{a}$ & \\
\hline $3 / 3$ & 353 & 676 & 290 & 1,319 & 0.135 & 0.130 & 0.135 & 0.133 & $0.241(0.035)$ \\
\hline $3 / 4$ & 430 & 848 & 423 & 1,701 & 0.568 & 0.597 & 0.568 & 0.582 & $0.394(0.042)$ \\
\hline $4 / 4$ & 160 & 327 & 136 & 623 & 1.0 & 0.813 & 1.0 & 0.902 & $0.430(0.076)$ \\
\hline
\end{tabular}

Weighted for sample sizes of parents, sibs, and offspring. 
Table 5. Estimated Lifetime Risk of $A D$ among First-Degree Relatives Stratified by Sex of the Proband. Sex of the Relatives. and ApoE Genotype of the Proband

\begin{tabular}{|c|c|c|c|c|c|c|}
\hline \multirow[b]{2}{*}{ Group } & \multicolumn{2}{|c|}{ No. of Relatives } & \multirow{2}{*}{$\begin{array}{l}\text { Oldest Onset } \\
\text { Age }(\mathrm{yr})\end{array}$} & \multirow[b]{2}{*}{ Lifetime Risk (SE) } & \multicolumn{2}{|c|}{ Comparison $^{a}$} \\
\hline & Affected & Unaffected & & & Age & Risk (SE) \\
\hline \multicolumn{7}{|c|}{ Male probands } \\
\hline 833 & 34 & 458 & 96 & $0.573(0.168)$ & 82 & $0.134(0.031)$ \\
\hline$\varepsilon 34$ & 60 & 538 & 90 & $0.439(0.078)$ & 81 & $0.256(0.034)$ \\
\hline$\varepsilon 44$ & 20 & 206 & 82 & $0.283(0.064)$ & 82 & $0.283(0.064)$ \\
\hline \multicolumn{7}{|c|}{ Female probands } \\
\hline$\varepsilon 33$ & 47 & 780 & 93 & $0.267(0.070)$ & 82 & $0.151(0.026)$ \\
\hline$\varepsilon 34$ & 95 & 1,002 & 93 & $0.477(0.078)$ & 82 & $0.248(0.027)$ \\
\hline$\varepsilon 44$ & 41 & 356 & 91 & $0.527(0.112)$ & 82 & $0.328(0.054)$ \\
\hline \multicolumn{7}{|c|}{ Male relatives } \\
\hline$\varepsilon 33$ & 28 & 640 & 96 & $0.334(0.179)$ & 83 & $0.140(0.032)$ \\
\hline$\varepsilon 34$ & 48 & 801 & 93 & $0.351(0.090)$ & 84 & $0.170(0.030\rangle$ \\
\hline$\varepsilon 44$ & 27 & 291 & 91 & $0.526(0.182)$ & 84 & $0.330(0.070)$ \\
\hline \multicolumn{7}{|c|}{ Female relatives } \\
\hline$\varepsilon 33$ & 53 & 596 & 93 & $0.374(0.072)$ & 84 & $0.206(0.033)$ \\
\hline$\varepsilon 34$ & 107 & 739 & 92 & $0.538(0.068)$ & 84 & $0.348(0.034)$ \\
\hline$\varepsilon 44$ & 34 & 271 & 85 & $0.409(0.067)$ & 84 & $0.374(0.061)$ \\
\hline
\end{tabular}

${ }^{\text {a }}$ See text for groups being compared.

for the relatives of $\varepsilon 3$ and $\varepsilon 4$ homozygotes were not significant $(Z=1.44, p=0.15$ and $Z=0.47, p=$ 0.64). Furthermore, Figure 3 shows that among male relatives the estimated risk for the ApoE 3/4 group was not different from the risk for the ApoE $3 / 3$ group but was about one half the risk for the ApoE $4 / 4$ group $(Z=2.10, p=0.036$ ). In contrast, among female relatives the risk for the ApoE $3 / 4$ group was nearly twice the risk for the ApoE $3 / 3$ group ( $Z=$ $3.00, p=0.0026$ ) but almost identical to the risk for the ApoE 4/4 group (Fig 4). Proportional hazards analyses revealed that male relatives of $3 / 3$ and $3 / 4$ probands have reduced risk of $A D$ compared with male relatives of $4 / 4$ probands (relative risk $[R R]=0.56$; $95 \%$ confidence limits $=0.35-0.91, p=0.018$ ). In contrast, female relatives of $3 / 4$ and $4 / 4$ probands had an increased risk of $\mathrm{AD}$ compared with female relatives of $3 / 3$ probands $(R R=1.90,95 \%$ confidence limits $=1.36-2.66, p=0.0002$ ).

\section{Discussion}

In this sample of 549 families, the risk of $\mathrm{AD}$ among first-degree relatives increases significantly with the number of ApoE $\varepsilon 4$ alleles present in the proband. These results support the hypothesis that the E4 isoform enhances disease susceptibility. However, the risk of developing $\mathrm{AD}$ does not correspond fully with the estimated proportion of $\varepsilon 4$ carriers among the relatives in this group of families. Among relatives of ApoE 3/4 probands, women have approximately twice the risk as men of developing $\mathrm{AD}$ by a given age.

Approximately two thirds of the probands in this study were ascertained from specialty clinics for mem- ory disorders participating in the MIRAGE Study and these subjects may not be representative of all $A D$ patients. Clinic patients tend to have younger ages at onset and be more educated than others. Although age at onset may be related to ApoE genotype, it is unlikely that either of these factors distorted the association between ApoE genotype of the proband, familial clustering of $\mathrm{AD}$, and gender. It is also possible that clinic patients are more likely to report a family history of dementia [32]. However, at age 90 the lifetime risk of $\mathrm{AD}$ in the relatives of MIRAGE patients (30.9 \pm $2.5 \%$ ) was less than the corresponding risk to relatives of the Dutch population-based patients $38.8 \pm$ $6.2 \%)$, but the difference was not significant $(p=$ $0.24)$. Another concern is that only one third of the MIRAGE patients at these centers were genotyped for ApoE. Although most of the remaining subjects were either deceased or no longer followed in the clinic, refusal of some to donate a blood sample may have introduced a selection bias associated with perceptions of family history of AD. This is also unlikely because the $30.9 \%$ risk for relatives of the 378 MIRAGE patients in this study is nearly identical to the corresponding risk estimated for relatives of the total sample of 1,694 MIRAGE patients $(32.9 \pm 1.3 \%)$ [33]

The observations that relatives of ApoE 3/3 probands have a $38 \%$ lifetime risk (to age 96 ) of developing $\mathrm{AD}$, but only $13 \%$ of these individuals are predicted to have at least one $\varepsilon 4$ allele, suggest that familial factors (genetic or nongenetic) independent of ApoE contribute substantially to disease susceptibility. van Duijn and coauthors [8] reported that both the number of $\varepsilon 4$ alleles and a family history of a first- 


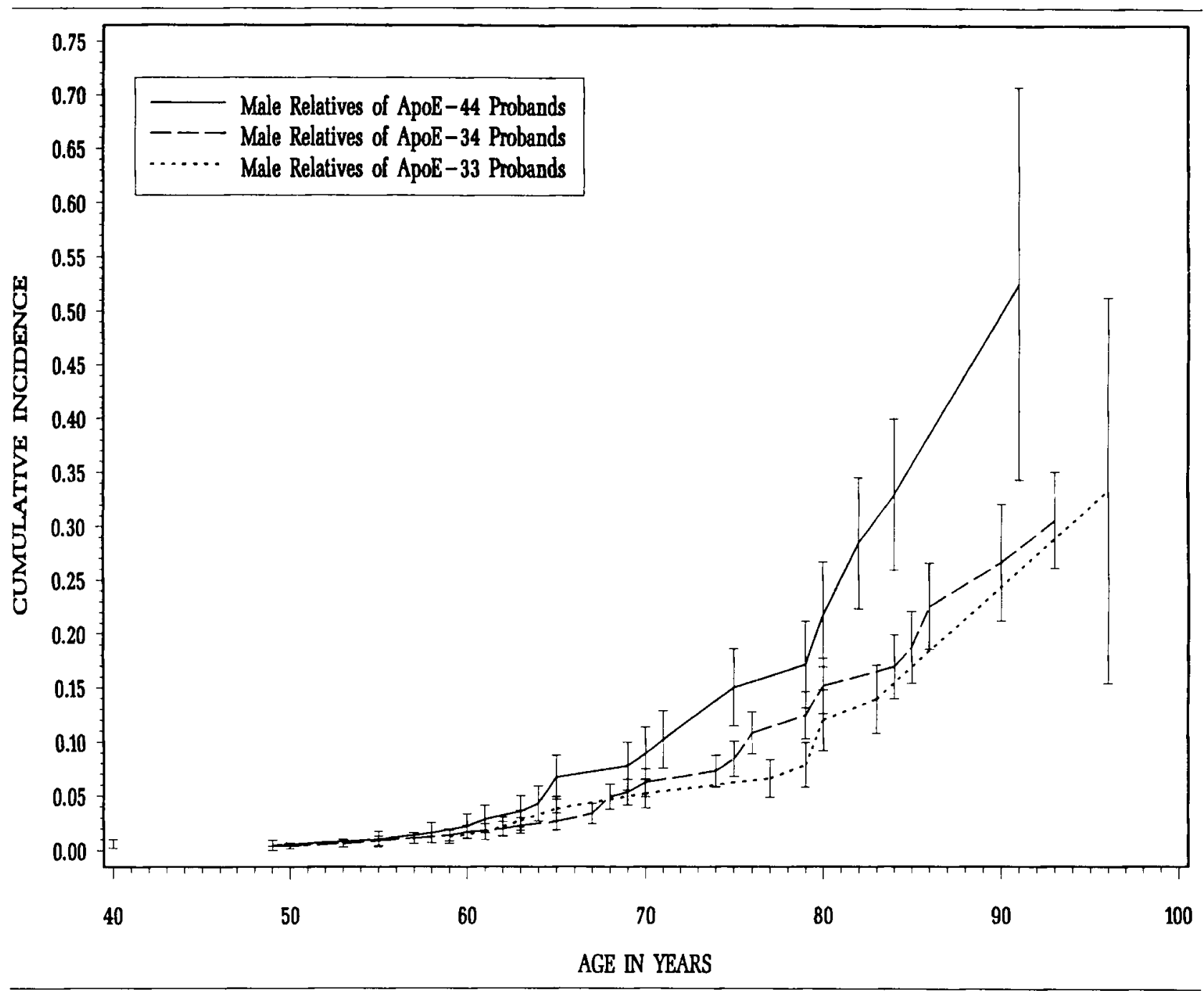

Fig 3. Estimated lifetime incidence of Alzheimer's disease (AD) in male first-degree relatives of $A D$ probands with $A$ poE $3 / 3$. ApoE 3/4. and ApoE 4/4 genotypes. Vertical lines sbove standard errors at each age value for onset in affected relatives.

degree relative with memory problems influence risk of early-onset $\mathrm{AD}$, but there is disagreement whether these two factors act additively or interact in the prediction of $\mathrm{AD}[34,35]$. It is likely that ApoE interacts with other molecules in the pathophysiology of $\mathrm{AD}$ given its important role in a variety of physiological pathways [36, 37]. Our lifetime risk data for ApoE $3 / 3$ probands and for relatives of affected members of families with familial late-onset $\mathrm{AD}[39,40]$, and genetic linkage studies $[37,38]$ support the existence of other $\mathrm{AD}$ genes that may interact with $\mathrm{ApoE}$.

Although our data demonstrate a significant increase in risk of disease among relatives with dose of $\varepsilon 4$ in the proband (see Table 3), the 7 to $10 \%$ increase in risk for each $\varepsilon 4$ allele in the proband is much less than expected if the E4 isoform was sufficient to cause disease in all people. In fact, the lifetime risk estimate

of $44 \%$ among first-degree relatives of ApoE $4 / 4$ probands suggests that after adjusting for censored observations, as many as $50 \%$ of people having at least one $\varepsilon 4$ do not develop AD. Approximately $66 \%$ of the relatives in this group are predicted to have the ApoE $3 / 4$ genotype and $24 \%$ to be $\varepsilon 4$ homozygotes. Since none of the relatives were typed for $A$ poE, we cannot compare the risk of disease for relatives with $3 / 4$ versus $4 / 4$ genotypes. However, the fact that the risk by age 90 to relatives of $3 / 4$ probands, of whom only $7 \%$ are predicted to be $\varepsilon 4$ homozygotes, is only $4.4 \%$ lower than the risk to relatives of $4 / 4$ probands (see Table 4), indicates that a substantial proportion of persons with the $4 / 4$ genotype are cognitively normal at a very old age. This conclusion is supported by crosssectional population-based studies $[41,42]$. The disparity between risk of disease and proportion of $\varepsilon 4$ carriers may be attributed to an underestimate of dementia among relatives. This explanation is unlikely for two reasons. First, to maximize diagnostic certainty among relatives, we restricted our analysis to first- 


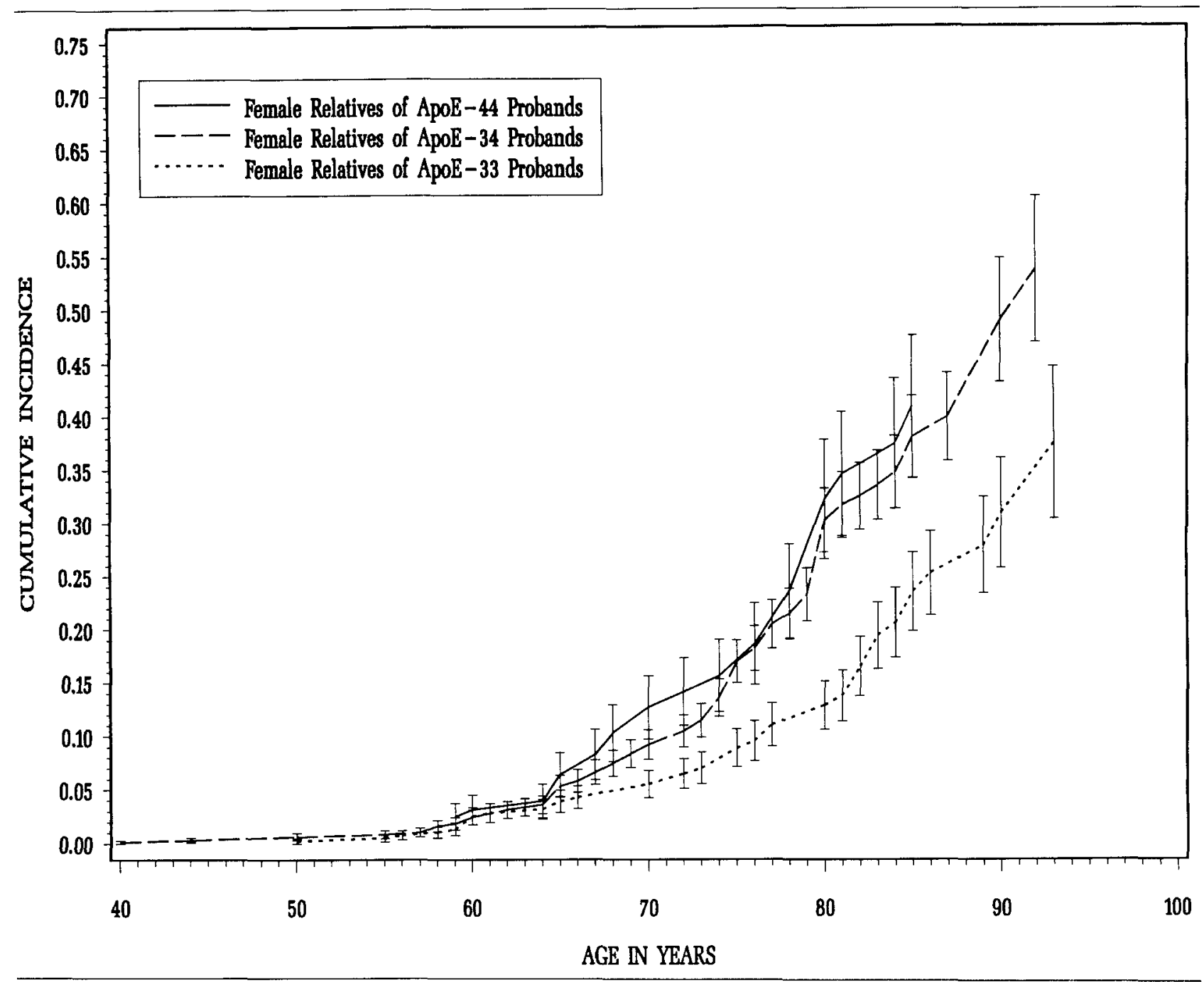

Fig 4. Estimated lifetime incidence of Alzbeimer's disease (AD) in female first-degree relatives of $A D$ probands with $A$ poE $3 / 3$, ApoE 3/4, and ApoE $4 / 4$ genotypes. Vertical lines show standard errors at each age talue for onset in affected relatives.

degree relatives, used mutliple informants, and reviewed medical and other records for all subjects suspected to have dementia. Second, since the relatives of ApoE 3/3 probands have a higher risk of disease than the expected proportion of $\varepsilon 4$ carriers, the degree of underestimation would have to vary by ApoE genotype, and there are no apparent reasons for this.

The finding that relatives of probands having ApoE genotype $2 / 2$ or $2 / 3$ have the same risk as relatives of ApoE $3 / 3$ probands does not support the evidence for a protective effect of the $\varepsilon 2$ allele on the risk of $A D$ [42-46]. However, our results are also not conclusive for the hypothesis of an increased risk associated with this allele [47-49]. There are several explanations why our analyses do not distinguish between these two hypotheses. First, the proportion of relatives having $\varepsilon 4$, and the $4 / 4$ genotype in particular, is the same for

ApoE 2/2, 2/3, and $3 / 3$ probands. Thus, although the proportion of relatives of ApoE $2 / 2$ or $2 / 3$ probands having $\varepsilon 2$ is estimated to be six to seven times higher than among relatives of $3 / 3$ probands, in the collective group of relatives whose individual genotypes are unknown, the effect (positive or negative) of $\varepsilon 2$ may have been masked by the detrimental effect of $\varepsilon 4$. Alternatively, a much larger sample of $\varepsilon 2$ probands may be needed to demonstrate a difference in lifetime risk of $\mathrm{AD}$ among relatives. It is also plausible that the effect of $\varepsilon 2$ on risk of $\mathrm{AD}$ may depend on other genetic or environmental factors. Our study sample includes patients from various ethnic backgrounds and geographic regions.

The trend of younger onset age among affected relatives with dose of $\varepsilon 4$ in the proband was not significant. In fact, because in our procedure mean onset age was estimated simultaneously with the lifetime risk, the means would have been even more similar had the maximum onset ages for each group been the same. Lack of a dose effect reflects, perhaps, a limitation of 
our study design for relating ApoE genotype in probands to risk of illness and expression in relatives. Alternatively, previous estimates for the onset age distribution of each ApoE genotype were biased because they were derived from members of families with lateonset familial AD [14]. This explanation is unlikely because although the distributions estimated from $\mathrm{AD}$ patient samples may be skewed from the true distributions, differences berween ApoE genotype groups should be the same. Moreover, a dose effect of $\varepsilon 4$ on age at onset is also supported by family studies [5052]. A more plausible explanation for our findings is that age at onset of $\mathrm{AD}$ is determined by a complex interaction of genetic and environmental factors (V. S. Rao and colleagues, unpublished manuscript 1995) of which only two (ApoE genotype and sex) were considered in the present study.

A gender difference in lifetime risk of $A D$ among relatives of $\varepsilon 4$ heterozygotes was observed previously in a study of 52 families with late-onset familial AD [53]; however, the relative differences in risk attributable to ApoE genotype were relatively small compared to other factors because men and women in those families lacking $\varepsilon 4$ had a lifetime risk of $A D$ of at least $70 \%$. Duara and coworkers [54] also found that the proportion of affected women versus affected men was higher for relatives of probands having the ApoE 3/4 genotype than for relatives having the ApoE $3 / 3$ genotype. The apparently reduced risk of $\mathrm{AD}$ among male relatives of ApoE 3/4 probands may be due to the association of hypercholesterolemia and coronary heart disease with ApoE $\varepsilon 4$ [55-57]. Males with $\varepsilon 4$ who have an increased risk of $\mathrm{AD}$ may be underrepresented among the relatives because they are more likely than females to succumb to heart disease before reaching an age when $\mathrm{AD}$ would occur. However, this is probably not an explanation for our findings. Data from middle-age $($ mean $=48.7 \pm 10.2$ years, range $=21-77$ years) and elderly (mean $=76.4 \pm 5.9$ years, range $=67-95$ years) cohorts in the Framingham Study revealed only a slight reduction of the $\varepsilon 4$ allele frequency with age $[31,42]$. Other studies showing a significant age-related decrease in $\varepsilon 4$ did not indicate gender differences $[41,58,59]$.

Rather, our results suggest the presence of a sexmodification effect of the ApoE 4 isoform on disease susceptibility. Among women, a single copy of the $\varepsilon 4$ allele appears to be sufficient to elevate disease risk from baseline (i.e., risk of disease among persons having the ApoE $3 / 3$ genotype), whereas among men, a double dose of $\varepsilon 4$ is necessary to attain the same increase in risk. This hypothesis is supported by our findings from segregation analysis which suggest that after adjusting for gender differences in longevity, women are innately more susceptible than men to $A D$ [60]. Factors that may be specific to women, or act differently in women than men, and modify the deleterious effects of ApoE 4 include hormones such as estrogen [61], antiinflammatory drugs [62], and cholesterol [36]. Studies of the interaction of these factors with ApoE may provide important clues for preventing onset of the disorder.

Our findings have important clinical implications. An individual may have an affected parent or sibling who is diagnosed with $A D$ and wishes to know his or her risk based on the ApoE genotype of the affected family member. On the basis of data reported by Corder and associates [43], the sensitivity for diagnosing $\mathrm{AD}$ from the detection of two $\varepsilon 4$ alleles is $69 \%$ and the specificity is $72 \%[15]$. Our results suggest that the predictive value of ApoE genotype could be improved by incorporating information on the consultant's sex and residual genetic factors. Until tests for other genetic factors for $\mathrm{AD}$ are developed (amyloid precursor protein [APP] mutations and defects in chromosomes 1- and 14-linked genes are apparently rare causes of AD), one could incorporate a quantitative assessment of the person's family history [63] into the diagnostic test.

This work was supported in part by National Institutes of Health grants R01-AG09029 (to L. A. F.), P30-AG10130 (to the Alzheimer Disease Center at Emory University), R0L-AG1 1503 (to R. C. G.), AG05142 (to the Alzheimer Disease Research Center at the University of Southern California), P50-AG05134 (to J. H. G.), and R01NS31153 (to J. L. H.); a Zenith Award from the Alzheimer Association (to J. L. H.); The Netherlands Organization for Scientific Research (NWO); and the Flemish Biotechnology Program. Dr Wells was supported by a VA Merit Review. Dr van Broeckhoven is a research associate of the National Fund for Scientific Research (NFSR), Belgium.

We thank Elizabeth Foley, Beth Souza, Dr Nicola Lautenschlager, Dr Randi Jones, and Karhy Martelli for collecting family history information, and Jemma Williams for assistance in preparing the manuscript. Drs Wim Schulce, Teun Tanja, Rob Haaxma, Arie Lameris, Rolf Saan, and Helen de Bruijn, Micheline de Haes, Jeanette Kamman, Hilda Kornman, Hanneke van Meurs, and Caroline Valkenburg were involved in collecting the Dutch data. Hans van der Boom. Peter de Knijff, Louis Havekes, Marc Cruts, and Anita Wehnert are acknowledged for ApoE typing the Dutch patients. Dr Chris Zarow extracted DNA from USC autopsy samples. Brain tissue for the Bedford patients was obtained from the GRECC brain bank.

\section{References}

1. Evans DA, Funkenstein HH, Albert MS, et al. Prevalence of Alzheimer's disease in a community population of older persons. JAMA 1989;262:2551-2556

2. Breteler MMB, Claus JJ, van Duijn CM, et al. Epidemiology of Alzheimer's disease. Epidemiol Rev 1992;14:59-82

3. Goate A, Chartier-Harlin M-C, Mullan M, et al. Segregation of a missense mutation in the amyloid precursor protein gene with familial Alzheimer's disease. Nature 1991;349:704-706

4. Mullan M, Crawford F, Houlden $H$, et al. A pathogenic mutation for probable Alzheimer's disease in the APP gene at the $N$-terminus of $\beta$-amyloid. Nature Genet 1992;1:345-347

5. Murrell J, Farlow M, Ghetti B, Benson M. A mutation in the 
amyloid precursor protein associated with hereditary Alzhejmer's disease. Science 1991;254:97-99

6. Sherrington R, Rogaev EI, Liang Y, et al. Cloning of a gene bearing missense mutations in early-onset familial Alzheimer's disease. Nature 1995;375:754-760

7. Levy-Lahad E, Wasco W, Poorkaj P, et al. Candidate gene for chromosome 1 familial Alzheimer's disease locus. Science 1995; 269:973-977

8. van Duijn CM, de Knijff P, Cruts M, et al. Apolipoprotein E4 allele in a population-based study of early-onset Alzheimer's disease. Nature Genet 1994;7:74-78

9. Saunders AM, Strittmatter WJ, Schmechel D, et al. Association of apolipoprotein $\mathrm{E}$ allele $\varepsilon 4$ with late-onset familial and sporadic Alzheimer's disease. Neurology 1993;43:1467-1472

10. Roses AD. Apolipoprotein $\mathrm{E}$ affects the rate of Alzheimer discase expression: $\boldsymbol{\beta}$-amyloid burden is a secondary consequence dependent on APOE genotype and duration of disease. J Neuropathol Exp Neurol 1994;53:429-437

11. Strittmatter WJ, Saunders AM, Goedert M, et al. Isoformspecific interactions of apolipoprotein $\mathrm{E}$ with tau and phosphorylated tau: implications for Alzheimer disease. Proc Natl Acad Sci USA 1994;91:11183-11186

12. Strittmatter WJ, Weisgraber KH, Goedert M, et al. Hypothesis: microtubule instability and paired helical filament formation in the Alzheimer disease brain as a function of apolipoprotein $\mathrm{E}$ genotype. Exp Neurol 1994;125:163-171

13. Rebeck GW, Reiter JS, Strickland DK, Hyman BT. Apolipoprotein $\mathrm{E}$ in sporadic Alzheimer's disease: allelic variation and receptor interactions. Neuron 1993:1 1:575-580

14. Corder EH, Saunders AM, Strittmatter WJ, et al. Gene dose of apolipoprotein $\mathrm{E}$ type 4 allele and the risk of Alzheimer's disease in late onset families. Science 1993;261:921-923

15. van Gool WA, Hijdra A. Diagnosis of Alzheimer's disease by apolipoprotein E genotyping. Lancet 1994;344:275

16. Farrer LA, Cupples LA, Blackburn S, et al. Interrater agreement for diagnosis of Alzheimer disease: the MIRAGE study. Neurology 1994;:44:652-656

17. McKhann G, Drachman D, Folstein $M$, et al. Clinical diagnosis of Alzheimer's disease: report of the NINCDS-ADRDA work group under the auspices of the Department of Health and Human Services Task Force on Alzheimer's Disease. Neurology 1984;34:939-945

18. van Duijn CM, Farrer LA, Cupples LA, Hofman A. Genetic transmission for Alzheimer disease among patients identified in a Dutch population based survey. J Med Genet 1993;30:640646

19. Hofman A, Schulte W, Tanja TA, et al. History of dementia and Parkinson's disease in 1st-degree relatives of patients with Alzheimer's disease. Neurology 1989;39:1589-1592

20. Farrer LA, O'Sullivan DM, Cupples A, et al. Assessment of genetic risk for Alzheimer's disease among first-degree relatives. Ann Neurol 1989;25:485-493

21. Farrer LA, Myers RH, Connor L, et al. Segregation analysis reveals evidence of a major gene for Alzheimer disease. Am J Hum Genet 1991;48:1026-1033

22. Wenham PR, Price $W H$, Blundell G. Apolipoprotein E genotyping by one-stage PCR. Lancet 1991;337:1158-1159

23. Locke P, Conneally PM, Tanzi RE, et al. APOE and Alzheimer disease: examination of allelic association and effect on age at onset in both early and late onset cases. Genet Epidemiol 1995; $12: 83-92$

24. Hixson JE, Vernier DT. Restriction isotyping of human apolipoprotein $\mathrm{E}$ by gene amplification and cleavage with $\mathrm{Hbal}$. J Lipid Res 1990;31:545-548

25. Cupples LA, Risch N, Farrer LA, Myers RH. Estimation of age at onset with missing information on onset. Am J Hum Genet $1991 ; 49: 76-87$
26. Kaplan EL, Meier P. Non-parametric estimation from incomplete observations. J Am Stat Assoc 1958:53:457-481

27. Sokal RR, Rohlf FJ. Biometry. San Francisco: WH Freeman, 1981

28. Kalbfleisch JD, Prentice RL. The statistical analysis of failure time data. New York: Wiley, 1980)

29. Cox DR. Regression models and life-tables (wich discussion). J R Stat Soc Ser B 1972;34:187-220

30. SAS User's Guide: Statistics. Cary, NC: SAS Institute, 1990

31. Ordovas JM, Lirwack-Klein L, Wilson PWF, et al. Apolipoprotein $\mathrm{E}$ isoform phenotyping methodology and population frequency with identification of apoE 1 and apoEs isoforms. J Lipid Res 1987;28:371-380

32. Rocca WA, Amaducci L. Epidemiology of Alzheimer's disease. In: Anderson DW, ed. Neuroepidemiology: a tribute to Bruce Schoenberg. Boca Raton: CRC Press, 1991:55-96

33. Lautenschlager NT, Cupples LA, Rao VS, et al. Risk of dementia among relatives of Alzheimer's disease patients in the MIRAGE study: what is in store for the "oldest old"' Neurology; 1960 (in press)

34. Jarvik GP, Wijsman EM. Alzheimer's disease and the family effect. Nature Genet 1994:8:115

35. van Duijn C, Van Broeckhoven C. Alzheimer's disease and the family effect-reply. Nature Genet 1994;8:115

36. Jarvik GP, Wijsman EM, Kukull WA, et al. Interaction of apolipoprotein $E$ genotype, total cholesterol level, and sex in prediction of Alzheimer disease in a case-control study. Neurology 1995:45:1092-1096

37. Kamboh MI, Sanghera DK, Ferrell RE, DeKosky ST. APOE*4 Associated Alzheimer's disease risk is modified by $\alpha 1$-antichymotrypsin polymorphism. Nature Genet 1995;10:486-488

38. Farrer LA, Myers RH, Cupples LA, et al. Transmission and age at onset patterns in familial Alzheimer's disease: evidence for heterogeneity. Neurology 1990;40:395-403

39. Locke PA, Haines JL, Corder EH, et al. Methods for detecting additional genes underlying Alzheimer disease. Am J Hum Genet 1994;55:A194

40. Yu C-E, Payami H, Olson JM, et al. The apolipoprotein E/C/ $\mathrm{CII}$ gene cluster and late-onset Alzheimer disease. Am J Hum Genet 1994;54:6.31-642

41. Kuusisto J, Koivisto K, Kervinen Mykkänen L, et al. Association of apolipoprotein E phenotypes with late onser Alzheimer's disease: population based study. BMJ 1994;309:636-638

42. Myers RH, Schaefer EJ, Wilson PWF, et al. Apolipoprotein E allele 4 is associated with dementia in a population based study: the Framingham Study. Neurology 1995 (in press)

43. Corder EH, Saunders AM, Risch NJ, et al. Protective effect of apolipoprotein $\mathrm{E}$ type 2 allele for late onset Alzheimer disease. Nature Genet 1994;7:180-184

44. Chartier-Harlin M-C, Parfitt M, Legrain S, et al. Apolipoprotein E, $\varepsilon 4$ allele as a major risk factor for sporadic early and late-onset forms of Alzheimer's disease: analysis of the 19q13.2 chromosomal region. Hum Mol Genet 1994;3:569-574

45. Talbot C, Lendon C, Craddock N, et al. Protection against Alzheimer's disease with apoe $\varepsilon 2$. Lancer 1994;343:1432-1433

46. Smith AD, Johnston C, Sim E, et al. Protective effect of apoE $\varepsilon 2$ in Alzheimer's disease. Lancet 1994:344:473-474

47. Sorbi S, Nacmias B, Forleo P, et al. ApoE allele frequencies in Italian sporadic and familial Alzheimer's disease. Neurosci Letr $1994 ; 177: 100-102$

48. Maestri G, Ottman R, Stern Y, et al. Apolipoprotein E and Alzheimer's disease: ethnic variation in genotypic risk. Ann Neurol 1995;37:254-259

49. van Duijn CM, de Knijff $P$, Wehnert $A$, et al. The apolipoprotein $\mathrm{E} \varepsilon 2$ allele is associated with an increased risk of early-onset Alzheimer's disease and a reduced survival. Ann Neurol 1995; 37:605-610 
50. Burgaonkar DS, Schmidt LC, Martin SE, et al. Linkage of lateonset Alzheimer disease with apolipoprotein E type 4 on chromosome 19. Lancet 1993;342:625

51. Hardy J, Houlden H, Collinge J, et al. Apolipoprotein E genotype and Alzheimer's disease. Lancet 1993;342:737-738

52. St. George-Hyslop P, McLachlan DC, Tuda T, et al. Alzheimer's disease and possible gene interaction. Science 1994;263:537

53. Payami H, Montee KR, Kaye JA, et al. Alzheimer's disease, apolipoprotein ع4, and gender. JAMA 1994;271:1316-1317

54. Duara R, Barker WW, Lopez-Alberola R, et al. Alzheimer's disease: interaction of apolipoprotein $\mathrm{E}$ genotype, family history of dementia, gender, cducation, ethnicity, and age at onset. Neurology 1996 (in press)

55. Leren TP, Borresen AL, Berg K, et al. Increased frequency of the apolipoprotein $\mathrm{E}-4$ isoform in male subjects with multifactorial hypercholesterolemia. Clin Gener 1985;27:458-462

56. Lenzen HJ. Assmann G, Buchwalsky R, Schulte $H$. Association of apolipoprotein E polymorphism, low-density lipoprotein cholesterol, and coronary artery disease. Clin Chem 1986;32:778781
57. Van Bockxmeer FM, Mamotte CD. Apolipoprotein epsilon 4 homozygosity in young men with coronary heart disease. Lancet 1992;340:879-880

58. Davignon J, Bouthillier D, Nestruck A, Sing C. Apolipoprotein E polymorphism and atherosclerosis: insight from a study in octogenarians. Trans Am Clin Assoc 1988;99:100-110

59. Cauley JA, Eichner JE, Kamboh MI, et al. ApoE allele frequencies in younger (age $42-50$ ) vs older (age $65-90$ ) women. Genet Epidemiol 1993;10:27-34

60. Rao VS, van Duijn CM, Connor-Lacke L, et al. Multiple etiologies for Alzheimer disease are revealed by segregation analysis. Am J Hum Genet 1994;55:991-1000

61. Paganini-Hill A, Henderson VW. Estrugen deficiency and risk of Alzheimer's disease in women. Am I Epidemiol 1994:140) 256-261

62. Breitner JCS, Gau BA, Welsh KA, et al. Inverse association of anti-inflammatory treatments and Alzheimer's disease: initial results of a co-twin control study. Neurology 1994;44:227-232

63. Farrer LA. Cupples LA. Estimating the probability for major gene Alzheimer disease. Am J Hum Genet 1994;54:374-383 